\title{
Dominique Julia, Réforme catholique, religion des prêtres et « foi des simples ». Études d'anthropologie religieuse ( $\mathrm{XVI}^{\mathrm{e}}-\mathrm{XVIII}{ }^{\mathrm{e}}$ siècles)
}

Genève, Droz, coll. " Cahiers d'Humanisme et de Renaissance ", vol. 118, sous-coll. « Ad Deum », n 2, 2014, 528 p.

Jean-Pascal Gay

\section{CpenEdition}

Journals

Édition électronique

URL : https://journals.openedition.org/assr/27388

DOI : $10.4000 /$ assr. 27388

ISSN : $1777-5825$

Éditeur

Éditions de l'EHESS

Édition imprimée

Date de publication : 1 octobre 2015

Pagination : 319

ISBN : 978-2-7132-2515-4

ISSN : 0335-5985

Référence électronique

Jean-Pascal Gay, «Dominique Julia, Réforme catholique, religion des prêtres et « foi des simples ». Études d'anthropologie religieuse ( $\mathrm{xv1} \mathrm{e}^{\mathrm{e}} \mathrm{xV \textrm {III }}$ e siècles) », Archives de sciences sociales des religions [En ligne], 172 I octobre-décembre, mis en ligne le 25 mai 2016, consulté le 21 septembre 2021. URL : http://journals.openedition.org/assr/27388 ; DOI : https://doi.org/10.4000/assr.27388

Ce document a été généré automatiquement le 21 septembre 2021.

(C) Archives de sciences sociales des religions 


\section{Dominique Julia, Réforme} catholique, religion des prêtres et «foi des simples ». Études d'anthropologie religieuse $\left(\mathrm{XVI}^{\mathrm{e}}-\right.$ XVIII ${ }^{\mathrm{e}}$ siècles)

Genève, Droz, coll. « Cahiers d'Humanisme et de Renaissance », vol. 118, sous-coll. « Ad Deum », n 2, 2014, 528 p.

Jean-Pascal Gay

\section{RÉFÉRENCE}

Dominique Julia, Réforme catholique, religion des prêtres et « foi des simples ». Études d'anthropologie religieuse ( $\mathrm{XVI}^{\mathrm{e}}$-XVIII ${ }^{\mathrm{e}}$ siècles), Genève, Droz, coll. « Cahiers

d'Humanisme et de Renaissance », vol. 118, sous-coll. « Ad Deum », n² 2, 2014, 528 p. 
1 Le volume rassemble dix textes inégalement répartis dans la carrière de Dominique Julia et publiés initialement entre 1972 et 2007. L'ensemble n'entend pas représenter tout le travail historique de l'auteur mais se concentre sur l'histoire religieuse. Les textes sont volontairement répartis thématiquement et non chronologiquement. La première partie («Historiographie, Débats, Sources et Méthodes ») contient notamment deux bilans historiographiques, l'un paru dans le célèbre volume Faire de l'Histoire de 1974 où se trouve par ailleurs celui d'Alphonse Dupront sur l'anthropologie religieuse et le bilan paru en 2000 dans la Revue d'Histoire de l'Église de France à l'occasion du colloque. L'autre texte méthodologique porte lui sur un des thèmes essentiels de l'ouvrage : celui des sources de la religion populaire et de l'interprétation de l'histoire du conflit entre orthodoxie cléricale et religion populaire.

2 La seconde partie intitulée "La réforme catholique. Problèmes d'ensemble » rassemble des études synthétiques sur les dynamiques historiques qui travaillent la réforme catholique : les rapports sociaux internes au clergé et le rapport à la communauté, avec déjà en ligne de fuite la question des conflits de cultures qui viennent à caractériser le catholicisme moderne; la constitution d'une culture cléricale; la discipline ecclésiastique et la canalisation de la dévotion populaire depuis Trente.

3 Les mêmes thèmes traversent les deux études de cas qui constituent la troisième partie "Situations et figures": l'étude du clergé rémois et ainsi des conditions sociales et culturelles qui rendent possible le geste de Jean Meslier qui rabat l'idéal tridentin du bon prêtre à une fonction d'utilité sociale ; l'autre étude qui complète cette partie est la plus récente du volume, celle qui porte sur le Miracle parisien de 1725 au Faubourg Saint-Antoine, de l'analyse duquel se dégagent les dynamiques de tensions et de crises qui travaillent le catholicisme français.

4 La dernière partie "Configurations nouvelles", distinguée comme telle, vient alors conclure l'ensemble et reprendre des questions posées en introduction et en première partie. Les deux textes correspondent à un moment historiographique bien précis, immédiatement antérieur au tournant historiographique de 1989. La première étude (« Déchristianisation ou mutation culturelle») reprend en proposant de se débarrasser $\mathrm{du}$ vocable "christianisation ", la question du détachement du catholicisme et du passage d'un régime religieux qui est celui des chrétientés rurales à celui des opinions religieuses. Elle insiste sur les dynamiques sociales qui président au phénomène : et notamment les phénomènes de circulations entre la ville capitale et les paroisses. Dans le cas du bassin Parisien, ce qui importe n'est pas seulement le jansénisme mais surtout ce que le jansénisme manifeste: l'extranéité du clergé dans la communauté et la politisation des rapports intraecclésiaux. La dernière étude («Les deux puissances. Chronique d'une séparation de corps ») s'attache à montrer comment la théorie des deux puissances cesse d'être opératoire dans la seconde moitié du XVIII siècle et comment la reconfiguration des rapports entre Église et État entérine avec retard les 
nouveaux partages du sacré et du profane qui résultent des dynamiques qui sont étudiées dans le reste du volume.

5 L'ouvrage ne donne pas à voir simplement un parcours historique à travers les étapes de l'historiographie religieuse française, dont D. Julia dégage une chronologie claire, articulée à la chronologie générale de l'historiographie française mais aussi à celle du rapport entre catholicisme et sciences sociales. Il pose de plus la question du lien entre des méthodologies historiques et des positionnements religieux. Il signale bien comment l'assomption de la sociologie religieuse ne se traduit pas nécessairement par la mise à distance des catégories indigènes au monde catholique et par une fragilisation aussi efficace que le proclament parfois certains historiens catholiques de la contrainte apologétique.

6 La logique de la collection donne au volume un profil très nettement disciplinaire qui constitue l'objet « histoire religieuse » d'une manière qui ne se retrouve en réalité pas dans l'ensemble du travail de D. Julia, notamment aussi en raison de la mise hors champ des travaux d'histoire de l'éducation et de leur profonde articulation avec l'histoire sociale du clergé. Ceci donne au volume un caractère paradoxal.

7 En effet, le volume renforce en partie la logique qui est bien celle de la présentation d'une thèse qui commande le volume et que reprend très clairement l'introduction dans l'étude de l'économie des basculements religieux entre temps moderne et période contemporaine. Deux débats ici sont essentiels, et bien posés dans le volume comme des débats qui soulèvent des problèmes de définition analogue : celui sur la «religion populaire " et celui sur la "déchristianisation». Dans un cas comme dans l'autre, D. Julia met en cause l'assomption du vocabulaire de l'orthodoxie tridentine par l'analyste qui vaut en réalité aussi bien souvent assomption des opérations de qualification et de domestication, centrales dans le déploiement de la réforme catholique elle-même. La question la plus caractéristique de ce point de vue est celle de la "déchristianisation ", posée dans des termes doctrinaux supposant une orthodoxie prédéfinie comme critère de mesure de la « christianisation ». Ce geste, écrit l'auteur, " confère au modèle théologique une valeur de décision redoublant l'élimination opérée par la hiérarchie ». Il place en retour l'historien dans une position impossible, celle d'un censeur ou "juge des reins et des cœurs». Or la thèse qui se dégage du volume met en avant une contradiction interne fondamentale à la réforme catholique française : la séparation entre religion des prêtres et « foi des simples » comme produit de la réforme elle-même.

8 En effet, l'un des points qui ressort le plus clairement de l'ouvrage est la manière dont le clergé devient un groupe construit par une culture commune. L'homogénéité culturelle du clergé et la stabilité du modèle clérical nouveau, qui transcendent les divisions partisanes, le placent en situation d'extranéité. La validation par le groupe clérical et par les autorités - y compris la validation d'une formation - passe par un conflit structurel avec la culture religieuse des communautés et notamment la culture festive. Ce conflit se traduit au final par un accroissement de la distance sociale incarnée dans l'opposition de ce prêtre qui fait dresser un paratonnerre sur son église et des communautés bigourdanes qui forcent leurs pasteurs à accomplir les rites religieux les protégeant des orages. La fragilité de la réforme catholique se trouve dans ce qu'elle a de cohérent, mais en retour ce sont bien les historiographies de la cohérence (apologétique ou non) du catholicisme que le travail de D. Julia a radicalement fragilisées. 
9 L'ouvrage, on le voit, offre une vraie leçon de méthode pour l'historien du religieux. La prudence historiographique s'y exprime à chaque moment, jusque dans l'usage du terme «catholicisme» que D. Julia entend bien ne constituer qu'en catégorie historiographique, nous signalant en creux la manière dont l'historien du religieux est parfois plus que d'autres menacé par l'essentialisme que portent avec lui ses catégories. 